\title{
Erratum to: Dynamic subtree tracing and its application in pay-TV systems
}

\author{
Peter Roelse
}

Published online: 9 July 2011

(C) Springer-Verlag 2011

Erratum to: Int. J. Inf. Secur. (2011) 10:173-187

DOI 10.1007/s10207-011-0126-5

Due to a production error, the following sentences were rendered incorrectly: the second sentence in Lemma 2 should have read: "Further, let $m=\sum_{i=0}^{\left\lfloor\log _{k} m\right\rfloor} b_{i} k^{i}$ be the representation of $m$ in base $k$, and let $w_{k}(m)$ denote the integer sum of all base $k$ digits of $m$ "; the last sentence of the second paragraph of Sect. 4.2.4 should have read: "If the available bandwidth in the transport stream is less than 2 Mbps, then the video streams in the transport stream can be compressed more, causing a slight reduction in their quality." Further, the first sentence after Corollary 1 should have read: "Measured in the total number of messages (with a message being either: a content segment variant, a tracing message or a revocation message), the computational cost for the head-end system and the bandwidth usage of Step 2 are $O\left(p^{2} \log n\right)$.”

The online version of the original article can be found under doi:10.1007/s10207-011-0126-5.

P. Roelse $(\varangle)$

Irdeto B.V., Taurus Avenue 105, 2132 LS, Hoofddorp, The Netherlands

e-mail: peter.roelse@irdeto.com 